\title{
Study on Education Method of Children's Stick Figure Drawing Based on Color Form
}

\author{
Yang Lin, Wang Chenyang \\ Nejiang Normal University, Zhang Daqian Academy of Fine Arts, 641100
}

Keywords: children; Brief strokes; Aesthetic education

\begin{abstract}
Culture turns people, and art raises the heart. Beauty education is an important content of children education. Facing the current situation of children education in China, there are some weak links in the aesthetics of children's painting. Taking children's stick figure drawing education as an example, it has better development space in the aspects of children's painting materials, the distribution of children's teachers and the guidance of children's painting. The investigation is carried out in the form of children's simplified Chinese painting in color, and a more systematic scheme is proposed to solve children's education problems, providing reference for children's art education.
\end{abstract}

\section{Research status of children's stick figure education}

The current studies on children in and out of the province can be summarized as the following three aspects:

1) researches on children education and its ontology. From the general situation, as far as the major databases collected by the author are concerned, the research on children education is more related to education, or the analysis of children's teaching principles, education concepts, or the analysis of children's psychological characteristics.

2) study the development model and development strategy of children education. According to the literature review, except for some rural children education ontology and development, most of the research on rural children education focuses on strategy research, and there are few practical studies on children art education.

3) the research on the cultivation of children's aesthetic ability by stick figure painting is relatively good, but there are few experts and scholars conducting theoretical research in this area. In rural children education, the cultivation of aesthetic ability is a weak link due to limited teachers and limited functions and conditions of aesthetic education.

\section{Children stick to the weak links of education}

At present, through case investigation and analysis, the number of class hours in primary school and kindergarten courses is less. This course mainly focuses on stick - brush painting. At the same time, there are some deficiencies in children's painting materials, teacher distribution and children's drawing guidance.

\subsection{Single painting materials for children}

At present, in primary school and kindergarten education, children's stick painting materials are mostly colored pencil, oil painting stick and so on. It's a universal way of drawing. However, there is no lack of materials for the creation of stick figure painting in life. In addition to using conventional painting materials in class, students should pay more attention to the development outside the classroom at ordinary times, so that students can walk into nature and find more and more diversified painting materials.

\subsection{Imbalance of teaching staff in children's stick painting}

Children's education is an important stage of knowledge initiation, the important role of teachers 
is self-evident. In the actual teaching process, teachers should not only teach students the skills of stick figure painting, but also cultivate their innovative ability, so that students can rely on their own thinking and collision of stick figure painting technology. [1] among the teaching team of children's stick figure painting, some teachers have not received formal training or learning, and their abilities in children's education are not enough. Stick figure painting belongs to the category of fine arts, which needs systematic training and professional accumulation. Therefore, if there is insufficient understanding of art knowledge in the teaching process of this part of teachers, the course of children's stick figure painting will make students insufficient and specific in the cognitive process. If some teachers fail to explain relevant knowledge throughout the teaching process, students will be allowed to aimlessly paint, adhere to the conventions, and then learn in a stylized and unitary way. Even can appear the circumstance that USES teaching material to copy mechanically. Among these art teachers, most of them are not art related professional teachers except a few art lovers who have been exposed to some basic knowledge of art. At present, there is a lack of professional art teachers for children's stick figure painting.

\subsection{The curriculum of simplified strokes is not balanced.}

In terms of course type, stick figure belongs to the category of art, and is an important part of student art education. In some primary schools, the course of simplified Chinese painting is not paid due attention to, there is no real implementation of the course. As a result, art education has been neglected in education. Under the guidance of examination subjects or the influence of one-sided development, some parents, students think that the standard of good students is the examination subjects' performance is good, the examination score should be high, and art accomplishment is not important. Look at art education courses in stick figure, art history, etc. Therefore, in the process of teaching, the course of sketch is often replaced by mathematics, physics and other courses. Study basically according to the idea of the examination, in order to improve the rate of enrollment under pressure, even some schools to stop short - brush painting courses. In this case, the development and learning of stick - brush painting class is limited. The status of art is weakened and the function and function of aesthetic education are neglected. In some rural areas, people have not yet realized the importance of art education due to limited conditions, so that some rural children have not received the cultivation of stick figure painting, leading to their lack in the process of art learning.

\subsection{The guiding role of teacher's teaching method is not enough}

Children's stick figure painting is an important part of children's art education. The stick figure mainly examines the writer's ability to generalize and express things. Children's stick figure painting focuses on the guidance and cultivation, so that most children have the freedom of painting and ideas. Some parents or teachers, due to lack of understanding of art education, give children a fixed definition of drawing works based on the one-sided criteria of whether the painting looks good or not. To a certain extent, it is a narrow and concise picture of textbook thinking, which inhibits children's creativity and imagination. As a facilitator to the textbook copy the book, according to the forced painting, simply according to the gourd painted on paper. Apply adult form esthetics idea to evaluate the children's artistic creation, to their creation influence. It not only suppresses the creative potential of the child, but also makes the child's thoughts become restrained, which is not conducive to the cultivation of beauty.

\section{The guidance and Educational Mode of simple Brushwork to Childrenundefineds Aesthetic cultivation}

In their childhood, children are keen in thinking and eager for new things. Their initial aesthetic ability and quality are gradually forming, which is the key to their enlightenment aesthetic education. However, the current conditions of teachers and training tend to cultivate their cultural courses, while ignoring the cultivation of their aesthetic quality, which makes the cultivation of students in the early stage of aesthetic value and aesthetic concept inadequate, bringing some problems to the comprehensive development of students. Beauty itself is vital, and the way it is 
delivered cannot be ignored.

Stick figure painting is a way to enrich the traditional classroom teaching. [2] stick figure painting is the product of the combination of the development of The Times and aesthetic education. As a form that children understand and love, stick figure painting can make children's aesthetic quality get better development. Guide children to pay attention to art education, so that they can cultivate their feeling, purify their mind and experience the truth, goodness and beauty while learning the culture course. It enables them to know, experience and feel beauty, and thus helps to cultivate their aesthetic sentiment and character. To be specific, we can improve the cultivation of children's stick figure painting from the following aspects.

\subsection{The expansion of the Creative Materials of the simplified Brushwork}

Children's learning does not require learners to master difficult skills or use complex technologies, but to lay a good foundation for children's aesthetic understanding. Traditional single materials cannot meet today's children, so we need to further increase and expand the original painting materials and tools. In terms of materials, traditional oil painting stick, watercolor, color lead and other creation methods can be changed. In terms of creating tools, children are encouraged to look for materials in life and in nature, such as drawing shapes with stones by the side of the road. Pick up fallen leaves and petals, and use the forms of rubbings and leaf stickers to create a sketch; Even the earth on the ground can be used as a panel and tool for painting.

Only when our vision is constantly broadened and various artistic concepts and styles meet, can art develop in a diversified direction, update traditional concepts and follow the changes of the situation. We must constantly absorb, learn and draw on new cultures to realize the integration of art, add new ways of artistic creation, pool the emotion and wisdom of creation, and realize the integration and collision in art. In the face of the same content, the same picture, everyone will have a different understanding and feelings, children and adults are also different. Play is the nature of children, children should be artistic creation appropriate content of play, guide children to play through the way of more in-depth thinking of things.

\subsection{Cultivation of teachers' ability in stick figure painting}

The creation and cultivation of children's stick figure painting is partly to let children's ability to wait for development, and partly to let children get the experience of beauty. These all need the guidance of good teachers. Good teachers can let the stick figure painting accompany the growth of children, form a deep accumulation, and harmonize art and life. The teaching and development of art course has experienced a long historical journey. With the change of productivity and technology, art course teaching is constantly updating education concept. [3] therefore, teachers of children education can use heuristic teaching methods and diversified creation methods in the teaching process to enable students to learn actively, love painting and creation, and promote the physical and mental development of children. Break the domestication type teaching situation, increase many kinds of comprehensive material skill drawing creation, form more diverse artistic creation way. Let children choose the artistic creation method and content, to find the education way suitable for children. For example, prepare to teach young children to draw pictures of the ocean instead of directly telling them what's in the ocean. Ask them, have the children seen the sea? What color is the sea? What lives in the sea? In this way, students can be inspired to think and encourage children to actively participate in learning.

Good teachers can use vivid language expression and body expression to guide and encourage rhythmically. Education is just part of the art education process. Good teachers can promote the development of children's creativity, imagination and observation, explore the potential ability of children, cultivate their creative thinking, and make children more interested in artistic creation.

\subsection{Expression of life emotion in stick figure}

Art can express our emotions. It can express our emotions and feelings. The development of children's stick figure painting is not only a course, but also a part of life. Like a diary around the children's side. Children's life is always colorful, and they always show their own feelings in life. 
We will see red moon, triangular cars, houses floating on the water, and other interesting ideas. The learning of children's stick figure painting should follow the age characteristics and psychological characteristics of children to encourage children to depict pictures in the painting form they most want to express, so that children can accept, understand and feel life.

Encourage children to incorporate painting in nature and daily life. Stick figure painting can make them easy to receive enlightenment and fully express their intelligence and creativity. When the boy was in a bad mood after a fall today, he was able to show his sadness by creating a sketch. For example, he would draw a gray flower, two brown clouds, several trees without leaves, etc., recording the mood of the creator. By observing the works of children during a period of time, he could effectively understand his heart, what he was thinking and what he wanted to do. At this time, the educator can effectively understand and care about what happens to the child, ask questions patiently, find out the problem, conduct emotional communication and guidance to the child, enlighten the child and help the child solve his problems. Children are encouraged to record their lives with a stick figure, breaking the traditional way of writing. Make it fun.

\section{Summarizes}

Children's stick figure painting is one of the ways to foster children's artistic creation, which is of great significance to children's aesthetic education. In language teaching, we can use a stick figure to illustrate the process of children's reading, listening, speaking and singing in language teaching. In mathematics teaching, the figures can be adapted into simplified Chinese characters and used in mathematics teaching. [4] aesthetic education needs to be built up slowly, not overnight. The cultivation of children's stick figure requires the joint efforts of society, school, parents and children. In the contemporary society, the attention of education department should be aroused first, and good education workers should be cultivated to promote parents' understanding of beauty. In a good atmosphere to slowly cultivate children's awareness of the stick painting. Use different creative materials to capture the details of life. Improve education method of children's traditional painting, use stick figure painting, and improve children's painting expression. Turn the art education work into practical ability, enrich children's emotions, mobilize children's enthusiasm and creativity. Gradually cultivate children's feeling and performance of beauty. Let children in the study of cultural classes, through the use of stick - brush painting to feel and paint life, edify sentiment, beautiful painting childhood.

\section{Acknowledgement}

This paper is supported by the following projects, and is one of the project research achievements:

1) Research project of sichuan rural children education research center, study on the cultivation of children's aesthetic ability by animation stick painting, project number: NYJ20170620

2) Neijiang normal university college students' innovation and entrepreneurship training program "research on children's artistic creation based on the form of colored ink painting" project no.: X2018090

\section{References}

[1] mo shuqiao. Analysis on the teaching of simplified Chinese painting in preschool education professional art course [J]. Beauty and times (middle),2015(04):58-59.

[2] Yin hedong. Application strategy of simplified Chinese painting in primary school Chinese teaching [J]. Education and teaching research,2014,28(11):84-89.

[3] wang mo, zhang hai. Exploration of diversity of knowledge structure of art teachers -evaluation of art curriculum and teaching theory [J]. China education journal,2018(09):148.

[4] zhang zhongxue. Preliminary study on the comprehensive application of stick figure painting in 
children's education teaching [J]. Education and teaching research,2012,26(10):119-121. 